\title{
No significant mass loss in the glaciers of Astore Basin (North-Western Himalaya), between 1999 and 2016
}

\author{
Sher MUHAMMAD, ${ }^{1,2,3,4}$ ๑ Lide TIAN, ${ }^{1,2,3,5}$ Marcus NÜSSER $^{6}$ \\ ${ }^{1}$ Institute of International Rivers and Eco-security, Yunnan University, 650500 Kunming, China \\ ${ }^{2}$ Yunnan Key Laboratory of International Rivers and Transboundary Eco-security, Kunming 650091, China \\ ${ }^{3}$ Key Laboratory of Tibetan Environmental Change and Land Surface Processes, Institute of Tibetan Plateau Research, \\ Chinese Academy of Sciences, Beijing 100101, China \\ ${ }^{4}$ International Center for Integrated Mountain Development (ICIMOD), Kathmandu, Nepal \\ ${ }^{5}$ CAS Center of Excellence in Tibetan Plateau Earth Sciences, Beijing 100101, China \\ ${ }^{6}$ Department of Geography, South Asia Institute, Heidelberg University, Germany \\ Correspondence: Sher Muhammad <msher@ynu.edu.cn>
}

\begin{abstract}
Although glaciers in High Mountain Asia produce an enormous amount of water used by downstream populations, they remain poorly observed in the field. This study presents a geodetic mass balance of the glaciers in the Astore Basin (with differential GPS (dGPS) measurements on Harcho glacier) between 1999 and 2016. Changes near the terminus of Harcho glacier (below 3800 $\mathrm{m}$ a.s.l.) featured heterogeneous surface elevation changes, whereas the middle section shows the most negative changes. The surface elevation changes were positive above $4200 \mathrm{~m}$ a.s.l. The average annual mass balance was $-0.08 \pm 0.07 \mathrm{~m}$ w.e. $\mathrm{a}^{-1}$ derived from a dGPS and DEM comparison whereas Advanced Spaceborne Thermal Emission and Reflection Radiometer DEM-based results show a slightly positive, that is $0.03 \pm 0.24 \mathrm{~m}$ w.e. $\mathrm{a}^{-1}$ in the same period. In contrast, the terminus indicates a substantial retreat of $\sim 368 \mathrm{~m}\left(4.5 \mathrm{~m} \mathrm{a}^{-1}\right)$ between 1934 and 2016. The average mass balance of 19 glaciers $\left(>2 \mathrm{~km}^{2}\right)$ covering $\sim 60 \%$ of the total glaciers in the Basin exhibit no net mass loss in the period of 2000-2016 and follow a pattern similar to adjacent Karakoram glaciers.
\end{abstract}

KEYWORDS: glacier mass balance, glacier mapping, dGPS, remote sensing

\section{INTRODUCTION}

The temperature rise over the past few decades (Stocker and others, 2013) is alarming for glacial health globally including High Mountain Asia (HMA) (Bolch and others, 2012; Gardelle and others, 2013). Accelerated warming could affect glacier mass balances at high altitudes and intensify glacier melting (Mountain Research Initiative, Elevation Dependent Warming Working Group, 2015). Such changes would impact future water availability; therefore, hydrological and cryospheric projections require precise glacier mass-balance measurements (Lutz and others, 2016). However, in situ glaciological studies remain insufficient due to the extreme topography and hazardous environment. The valley glaciers in western Himalaya and Karakoram are mostly avalanche-fed, with no distinctive equilibrium line altitude (ELA) or accumulation zones (Hewitt, 2007, 2011). These glaciers share similar morphologies and have extensive debris coverage (Shroder and others, 2000), making it difficult to determine their mass balance using most ground-based methods.

Direct measurements are vital for estimates of future water availability and food security (Kaser and others, 2006; Immerzeel and others, 2013) but the only hydrological mass-balance measurements in the northwestern Himalayan and Karakoram regions of the Indus Basin exist for the Siachen glacier from 1986 to 1990 (Bhutiyani, 1999; Zaman and Liu, 2015). Field-based geodetic studies using differential GPS (dGPS) and other instruments provide consistent estimates of glacier health (Kaser and others, 2006; Cogley, 2009; Tian and others, 2014; Muhammad and Tian, 2016), but recent in situ dGPS measurements $(2014 / 15)$ are restricted to the ablation zone for the Sachen glacier of the Astore Basin (Muhammad and Tian, 2016). Earlier studies investigated the Astore Valley during 1984, 1993, 1995-97, 2006 and 2010 but focused on the velocities, fluctuations, debris cover and mechanisms of rock glacier formation (Shroder and others, 2000; Nüsser and Schmidt, 2017). Dynamics of the Chungphare glacier were studied for the years 1934, 1958, 1987 and 2010 using repeat photography and multi-temporal mapping (Nüsser and Schmidt, 2017). Hence, field-based glacier mass-balance measurements are still lacking in the study region (Farhan and others, 2015; Muhammad and Tian, 2016).

Available glacier observations indicate that Himalayan glaciers have experienced melting and retreat in recent years (Kulkarni and Bahuguna, 2002; Fujita and Nuimura, 2011; Gardner and others, 2013; Vijay and Braun, 2016; Schmidt and Nüsser, 2017). Several studies have derived glacier length and area changes to better understand their dynamics in response to climate change (Kulkarni and others, 2011; Muhammad and others, 2013; Rankl and others, 2014; Khan and others, 2015), however, these changes represent an indirect and delayed response to climate change, varying from years to decades (Pratap and others, 2016; Zhu and others, 2019). Geodetic mass balance from surface elevation change data provides a more direct assessment of climate-induced glacier changes (Oerlemans, 2001; Bonanno and others, 2014). However, the temporal coverage of such studies using remote-sensing 
data are mostly very limited (Gardelle and others, 2013; Rankl and others, 2014; Kääb and others, 2015; Bolch and others, 2017) and have involved negligible ground validation. Although recent observations have extended the spatial coverage, detailed temporal coverage is missing for each region, and so only provide an overview of the largescale regional mass balance (Brun and others, 2017). Furthermore, validation and comparison of such measurements in the field are still lacking and strongly needed (Kulkarni and Bahuguna, 2002; Bhambri and Bolch, 2009; Muhammad and others, 2013; Kääb and others, 2015; Khan and others, 2015).

Therefore, this study attempted to evaluate the current behaviour of glaciers in the north-western Himalaya in the field. A debris-covered valley glacier was selected to represent the behaviour of regional glaciers since a majority of them are debris-covered at lower elevations. This study investigates Harcho glacier surface elevation changes over the past 17 years (1999-2016). We also use our results to validate the mass balance of observed glaciers (with area $\geq 2 \mathrm{~km}^{2}$ ) in the Astore Basin derived by Brun and others (2017) using Advanced Spaceborne Thermal Emission and Reflection Radiometer (ASTER) DEM. Furthermore, this work combined available historical data from a 1934 topographical map with more recent photographs taken in 1994 and a high-resolution QuickBird image of 2016 to track terminus changes. The study improves our understanding of the current glacier mass-balance changes in the region providing data on surface elevation change and mass balance.

\section{STUDY AREA}

Astore Basin is in the extreme west of Himalaya and upper Indus River Basin, located in the Nanga Parbat area in northern Pakistan. The catchment area of the Astore Basin is $\sim 3995 \mathrm{~km}^{2}$, with glaciers covering $\sim 252 \mathrm{~km}^{2}(6.3 \%$ of the catchment area), as per Landsat imagery (Path/Row: 149/036) from September 2000, or $258 \mathrm{~km}^{2}$ (6.5\%) from the Randolph Glacier Inventory version 6 (RGI6.0 released in 2017). Approximately 45\% of the glacier-covered area comprises small cirque-type glaciers. The remaining $55 \%$ of the total glacierized area in the basin is covered by 13 debris-covered valley glaciers. Farhan and others (2015) estimated the glacier-covered area of the Astore Basin to be $\sim 14 \%$ of the basin, which is more than double of the RGI6.0 and our estimates. The partially debris-covered Harcho glacier is located in the northwestern Himalaya between $35^{\circ} 21^{\prime}-35^{\circ} 23^{\prime} \mathrm{N}$ and $74^{\circ}$ $43^{\prime}-74^{\circ} 46^{\prime} \mathrm{E}$ (Fig. 1), near to the junction of the Himalaya, Hindukush and Karakoram ranges. The glacier was chosen as a regional representation of the study area, in which most of the glaciers have similar morphologies. The $4.8 \mathrm{~km}$ long Harcho glacier covers an area of 2.84 $\mathrm{km}^{2}$, with surface elevations ranging from 3750 to 4965 $\mathrm{m}$ a.s.l. The debris-covered and clean-ice portions of the glacier represent $\sim 38$ and $62 \%$ of the total area, respectively. Figure 1 also highlights glaciers that were studied by Brun and others (2017) as their results will be compared with this study. Figure 2 contains historical photos taken in 1934 (Fig. 2a), 1994 (Fig. 2b) and Harcho glacier surface (debris cover and clean ice) captured by sentinel-2 satellite on 28 October 2016 (Fig. 2c).

\section{DATA AND METHOD}

We present mass-balance data for Harcho glacier and compare/validate these results with glaciers in the Astore Basin ( $\geq 2 \mathrm{~km}^{2}$ area), derived by Brun and others (2017), using ASTER DEM data from the same observation period. The dGPS-based glacier surface elevation measurements were performed from the glacier terminus upwards for a length of $3.9 \mathrm{~km}$, thereby capturing a majority of the total length $(4.8 \mathrm{~km})$ of the glacier. The thickness change for the rest of the glacier was extrapolated based on the gradient of elevation change assuming surface elevation change as a function of altitude (Gardelle and others, 2012) to estimate the mass balance of the entire glacier. The following subsections describe the methodology for processing satellite images and DEM, dGPS survey of Harcho glacier, SRTM penetration correction, mass-balance estimation and uncertainty estimation.

\subsection{Satellite images and DEM}

This study mainly utilizes SRTM 30-m non void-filled DEM and dGPS data for the surface elevation change and massbalance estimates. The glacier boundary was derived from the Sentinel-2 image acquired on 28 October 2016 and provided by the Copernicus Programme (Copernicus). The $10 \mathrm{~m}$ resolution of the Sentinel-2 data helped to precisely identify glacier boundaries. The insignificant changes in the glacierized area of the Astore Basin during the study period (Farhan and others, 2015) was corroborated using the Sentinel-2 data that were appropriate for this purpose. Among the 16 bands, spectral bands $2-4$ (visible) and band 8 (NIR) have 10-m spatial resolutions. The Sentinel Application Platform (SNAP) was used to process the Sentinel data, and the subsequent extraction of the glacier boundary was performed by manual digitization in ArcGIS using RGB-842. The glacier was also classified into debriscovered and debris-free ice using the same Sentinel-2 image by manual digitization. The SRTM DEM is the first high-resolution near-global DEM acquired for the year 2000 based on data acquired between 11 and 22 February and has been available with a $30 \mathrm{~m}$ resolution since 23 September 2014 through Earth Explorer (http://www.earthex plorer.usgs.gov). The vertical data of the dGPS were converted to the EGM96-geoid, making the results comparable with the SRTM-based elevations. The conversion from EGM96 to ellipsoid heights was performed using the National Geospatial-Intelligence Agency (NGA) EGM96 model.

\subsection{DGPS survey}

The dGPS data were acquired during a glacier expedition with the help of local porters in September 2016. Due to the remoteness of Harcho Valley, the expedition reached as far as Rama in the Astore Valley (3200 m a.s.l.). The glacier was surveyed after following an $\sim 9.5 \mathrm{~km}$ path and crossing a $4000 \mathrm{~m}$ a.s.l. ridge to the south-east. A NavCom Starfire (SF-3050) differential GPS receiver was used for the survey, providing position and height information with accuracies of no more than $0.05 \mathrm{~m}$ (Muhammad and Tian, 2016). A choke-ring antenna (P/N: 82-001020-3001 LF) was mounted on a mast to avoid multipath errors during the dGPS survey and to acquire data with a vertical accuracy of $10 \mathrm{~cm}$ or better. All the dGPS data with a vertical accuracy 


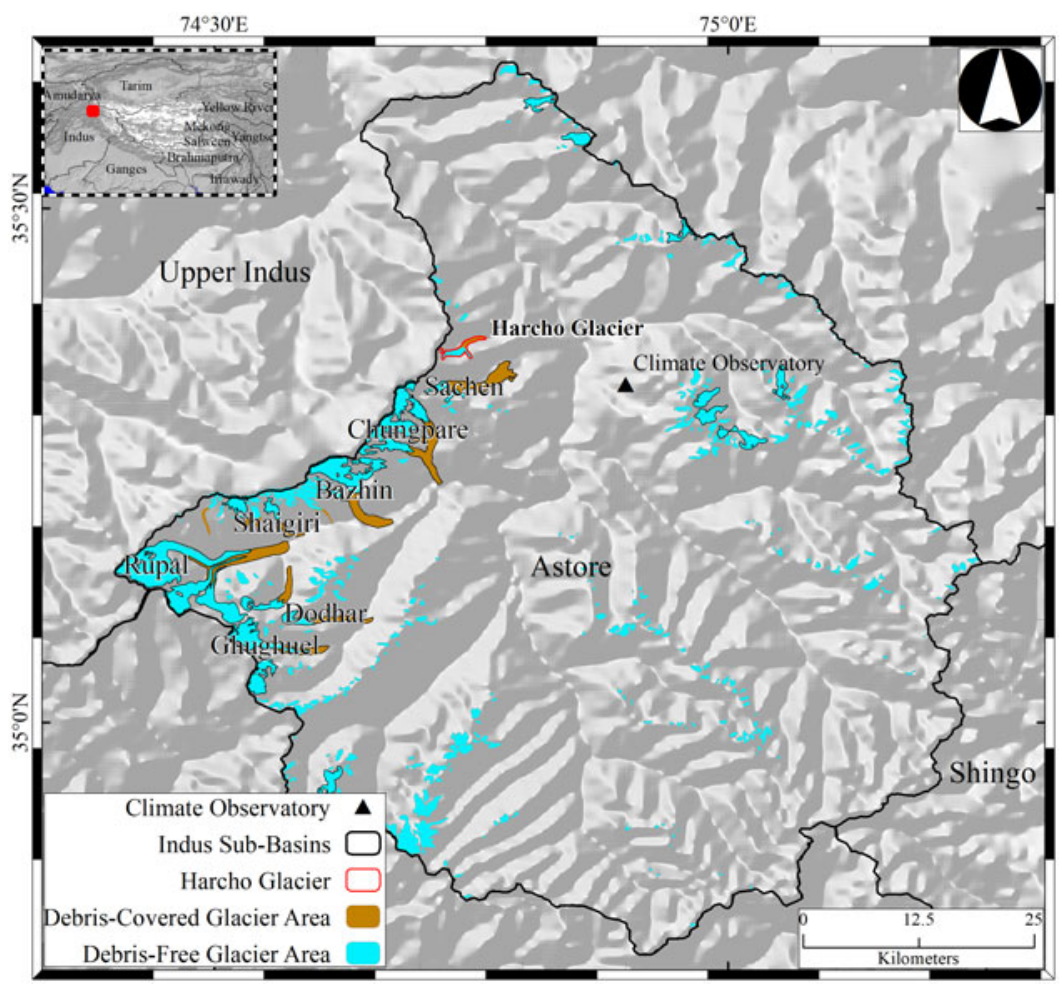

Fig. 1. Map showing Astore River Basin in the north-western Himalaya. All of the glaciers (debris-free and debris-covered) and the only climate observatory in the basin are presented. The mass balance of the Harcho glacier was observed in the field, whereas data for glaciers outlined in black are from Brun and others (2017).
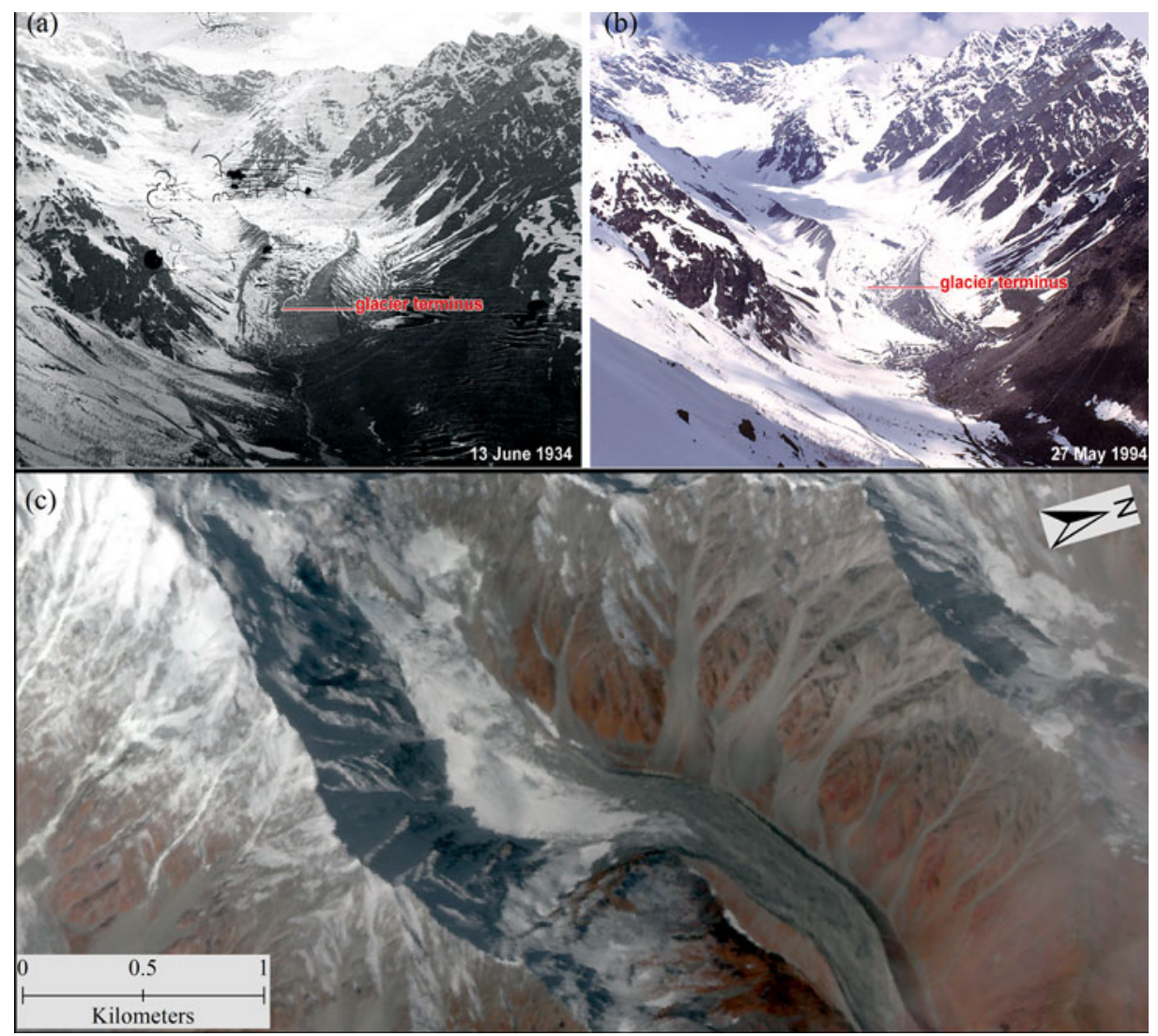

Fig. 2. Comparison of two photos (a) captured on 13 June 1934 (photo taken by Richard Finsterwalder) and (b) on 27 May 1994 (photo taken by Marcus Nüsser) showing the Harcho glacier (from terminus to top) and surroundings. Surface (debris cover and clean ice) of the Harcho glacier can be seen in a high-resolution Sentinel-2 image (S2A_MSIL1C_20161028T054932_N0204_R048_T43SDV_20161028T055734) acquired on 28 October 2016 (c). 
of $<10 \mathrm{~cm}$ were discarded before analysis. The tested accuracy of the dGPS instrument used in Tibet was within $\pm 6 \mathrm{~cm}$ (Zhu and others, 2014). The glacier surface was measured in transverse tracks to improve sampling and to minimize the errors by averaging the differences in the $50 \mathrm{~m}$ elevation bins with SRTM $30 \mathrm{~m}$ data. The pixel center position represents the pixel location of SRTM data, therefore overlapping dGPS points were compared within $3 \mathrm{~m}$ inside from each edge of the SRTM pixel to overcome possible geolocation errors, which are typically $<2 \mathrm{~m}$ (Rodriguez and others, 2006; Muhammad and Tian, 2016). The glacier was surveyed for 3 days, during which a total of 245 well-distributed data points were collected (Fig. 4). A survey of the valley near the glacier was also conducted, measuring 45 locations over the flat and gently sloping surfaces below the glacier terminus, within the elevation range 3496-3700 m a.s.l. Off-glacier data were used for validation and to make data comparable with the SRTM DEM data. The dGPS data were collected up to an altitude of $4370 \mathrm{~m}$ a.s.l. before the glacier was inaccessible due to crevasses and slope steepness. The SRTM elevations of the overlaid pixels were subtracted to estimate the surface elevation changes using Eqn (1).

$$
\Delta \boldsymbol{H}=H_{\mathrm{dGPS}}-H_{\mathrm{SRTM}}
$$

\subsection{SRTM penetration correction}

The SRTM C-band signal penetration into the glacier must be corrected to precisely estimate surface elevation change and mass balance (Gardelle and others, 2012; Kääb and others, 2015; Dehecq and others, 2016). The comparison of ICESat laser altimetry data with SRTM C-band data (Kääb and others, $2012 ; 2015)$ is widely used for SRTM C-band penetration estimates for the region. We assume that the February 2000 SRTM elevation represented the debris surface close to the end of the 1999 ablation period, considering penetration of the radar into the snow overlying the debris (Bolch and others, 2017). However, deeper radar penetration is expected in the clean ice surface even considering the February 2000 SRTM acquisition as representative of the 1999 late ablation period. We applied an average penetration estimate of $2 \mathrm{~m}$ in the studied region derived from the average of Jammu and Kashmir (1.4 m) and the Karakoram $(2.4 \mathrm{~m})$ because the study area lies within these regions and there are no C-band penetration estimates specifically for our study area (Kääb and others, 2012). The penetration bias was applied to $\sim 25 \%$ of the data corresponding to the clean ice surface of the glacier above $4000 \mathrm{~m}$ a.s.l.

\subsection{Mass-balance estimation}

After the penetration correction, the surface elevation change was converted into a mass balance in ice equivalent unit using Eqn (2) (Cogley and others, 2011).

$$
\dot{h}=\frac{\dot{b}}{\rho}-\nabla q
$$

where $\dot{h}$ is the surface elevation change, $\dot{b}$ is the mass balance, $\rho$ is the density of glacier ice, and $\nabla q$ is the horizontal gradient of the glacier. Because the data cover almost the entire glacier, the horizontal ice gradient was assumed to be zero. The mass balance becomes equal to the surface elevation change multiplied by the glacier ice density. This study assumes an $850 \pm 60 \mathrm{~kg} \mathrm{~m}^{-3}$ density throughout the glacier surface assuming a constant density vertical profile, as described by Sorge's law (Bader, 1954), as used in other studies (Gardelle and others, 2013; Bolch and others, 2017; Zhou and others, 2017). The mass balance was estimated at each measured location over the glacier surface. The point mass balance was then averaged over 50 m elevation contours for discrete data using Eqn (3) (Cogley and others, 2011).

$$
B=\frac{1}{S} \cdot \sum b_{\mathrm{n}} \cdot S_{\mathrm{n}}
$$

where $\mathrm{S}$ is the surface area and $b_{n}$ and $S_{n}$ are the mass balance and surface area intervals of each $50 \mathrm{~m}$ elevation contour band, respectively. The difference in data acquisition times in both the observation years (seasonal) of the two datasets is assumed to be equivalent to the SRTM penetration, making the mass-balance period equal to 17 years (1999 - 2016).

\subsection{Uncertainty estimation}

The maximum bound of the overall uncertainty in the surface elevation change and mass balance of the Harcho glacier was estimated using Eqn (4) (Bolch and others, 2017).

$$
E=E_{\Delta \mathbf{h}}+E_{\mathbf{a}}+E_{\mathbf{p}}+E_{\mathbf{m}}
$$

where $E_{\Delta \mathbf{h}}$ is the error due to elevation difference in the offglacier areas (comparing SRTM with dGPS data); $E_{\mathbf{a}}$ is the change in the glacier-covered area; $E_{\mathbf{p}}$ and $E_{\mathbf{m}}$ are the error in the penetration and density assumptions. $E_{\mathbf{a}}$ was considered to be negligible, assuming no significant difference in the actual and mapped glacier coverages. $E_{\Delta \mathbf{h}}$ was derived $\left( \pm 0.03 \mathrm{~m} \mathrm{a}^{-1}\right)$ by comparing off-glacier data from both the datasets. We estimated $E_{\mathbf{p}}$ to be $0.04 \mathrm{~m}$ w.e. $\mathrm{a}^{-1}$ (an uncertainty of $\pm 0.7 \mathrm{~m}$ in penetration estimate for the region (Kääb and others, 2012)) and $E_{\mathbf{m}}$ to be $7 \%\left( \pm 60 \mathrm{~kg} \mathrm{~m}^{-3}\right)$ of the elevation change (Huss, 2013; Bolch and others, 2017).

\section{RESULTS}

By comparing the differences in the measured dGPS data and the SRTM data, we estimated the glacier surface elevation changes, ranging between -17.2 and $+15.5 \mathrm{~m}$. More than $50 \%$ of the observed glacier surface elevation changes varied within $\pm 7 \mathrm{~m}$. The calculated glacier surface elevation changes are inhomogeneous in each of the elevation zones along the glacier. The thick debris-covered terminus exhibits slight surface elevation lowering with significant heterogeneity (Figs 3,4). Most of the debris-covered part shows a negative surface elevation change. However, the elevation changes vary positively from the middle to the upper (clean ice) zone of the glacier. A general negative surface elevation change characterizes the debris-covered ablation zone (from the terminus up to $4200 \mathrm{~m}$ a.s.I., as shown in Fig. 3), whereas positive changes occur in the clean ice portions of the glacier.

For the GPS-surveyed lower and mid sections of the glacier, the average annual elevation change relative to the SRTM DEM before penetration correction was $-0.20 \pm$ $0.18 \mathrm{~m} \mathrm{a}^{-1}$, and after correction was $-0.22 \pm 0.19 \mathrm{~m} \mathrm{a}^{-1}$. 


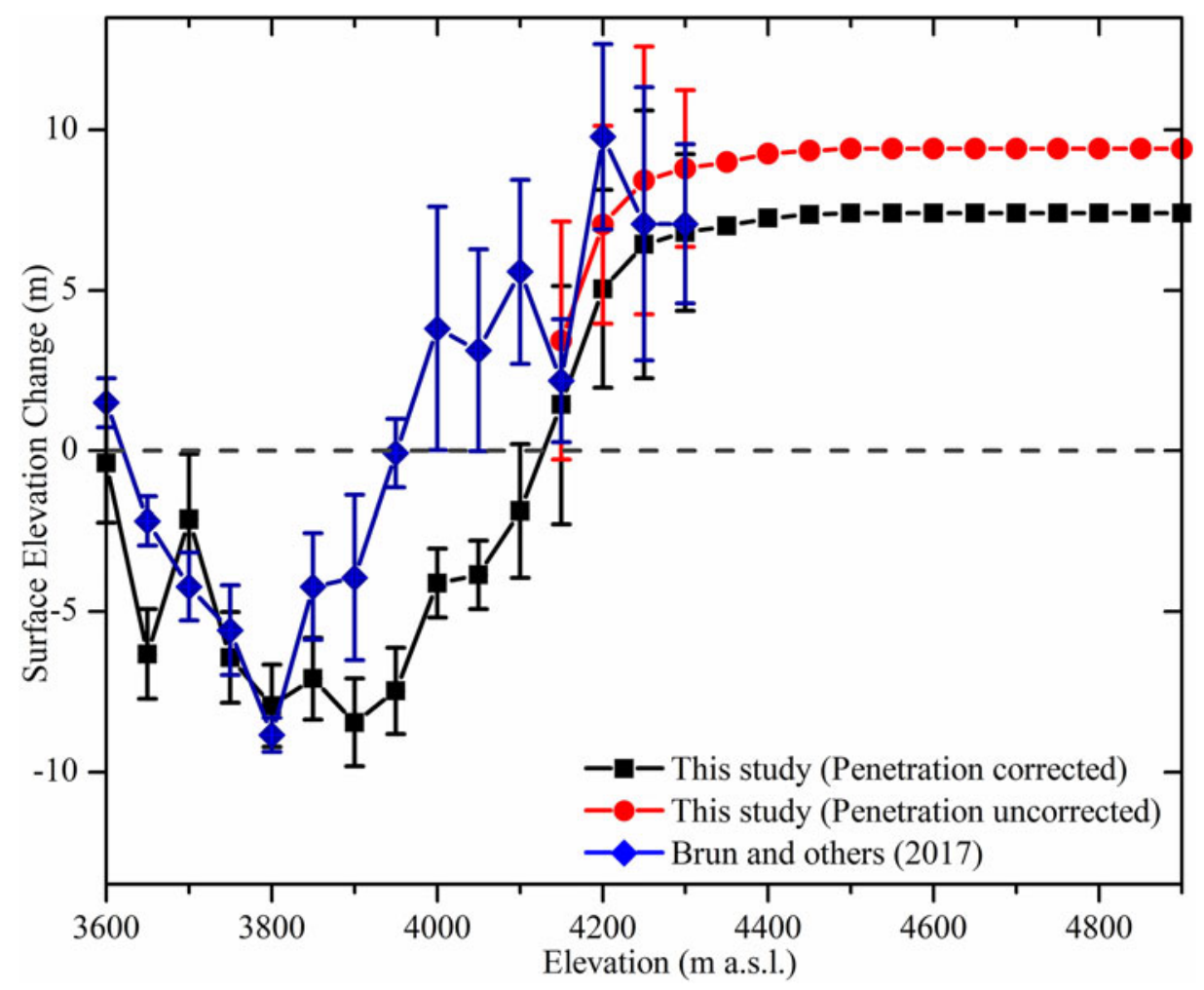

Fig. 3. Harcho glacier surface elevation changes $(\mathrm{m})$ in each 50-m elevation bin from the terminus to the top of the glacier. Error bars are derived from the uncertainties described in section 3.4, scaled according to the sample size in each bin. The line without error bars shows extrapolated surface elevation change $(\mathrm{m})$.

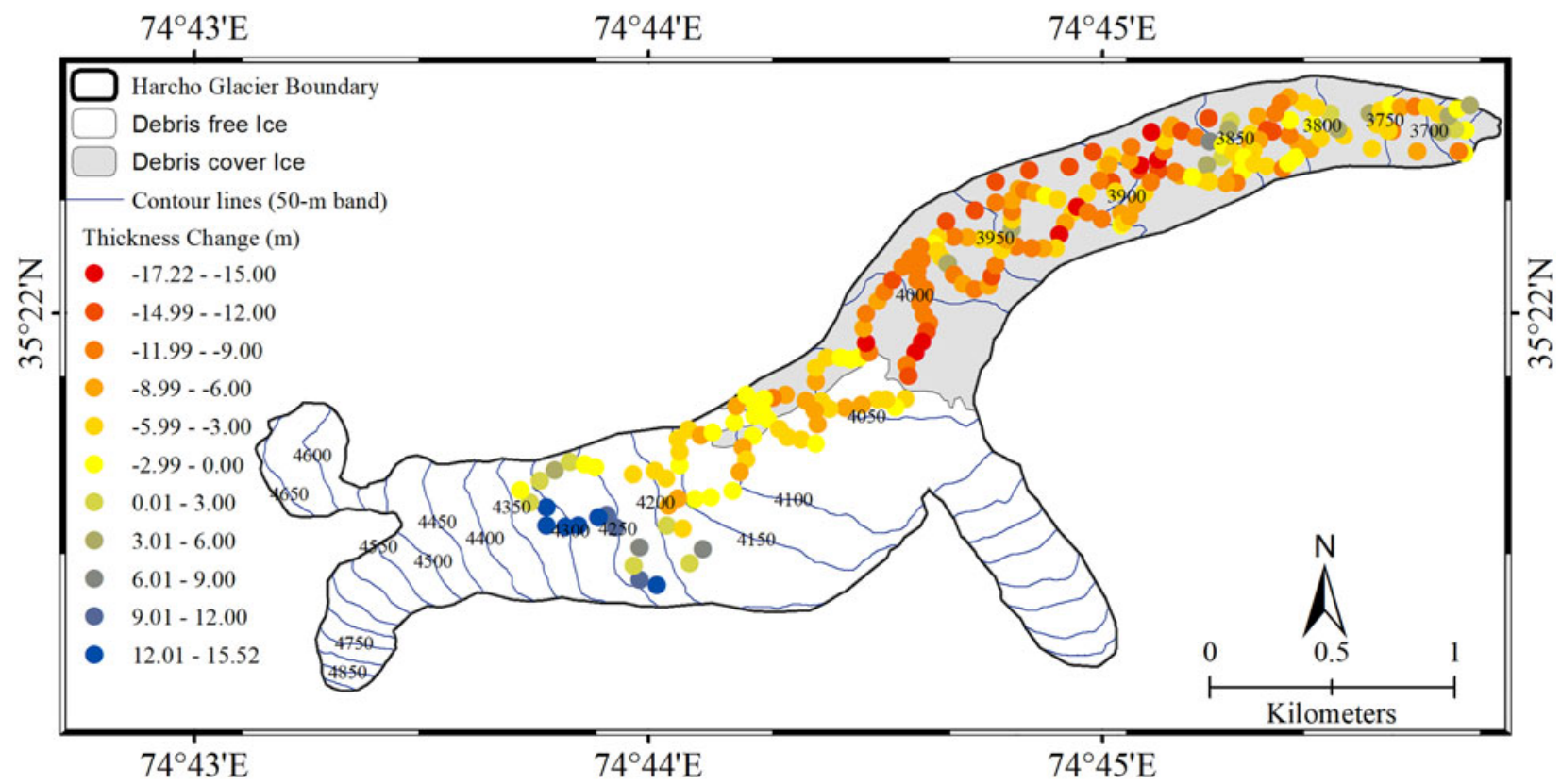

Fig. 4. Map of the glacier surface elevation change $(\mathrm{m})$ between 1999 and 2016 at all measured points on Harcho glacier. 50-m elevation contour lines are overlaid on the glacier. The debris-covered part of the glacier is shown with a grey background, and the debris-free zone is in white.

Extrapolating the height changes to cover the entire glacier, the mean annual surface elevation change was $-0.10 \pm$ $0.09 \mathrm{~m} \mathrm{a}^{-1}$ during 1999-2016. Conversions of the surface elevation change to the mass balance for the entire glacier based on the standard average density assumption (850 \pm $60 \mathrm{~kg} \mathrm{~m}^{-3}$ ) before penetration correction produce values of
$-0.05 \pm 0.07 \mathrm{~m}$ w.e. $\mathrm{a}^{-1}$ which is close to the penetrationcorrected mass balance $-0.08 \pm 0.07 \mathrm{~m}$ w.e. $\mathrm{a}^{-1}$ during the study period. Figure 3 shows the mean elevation changes from the terminus to the top of the glacier with 50 $\mathrm{m}$ elevation bins for each observed interval. The map in Figure 4 shows the spatial distribution of the surface 

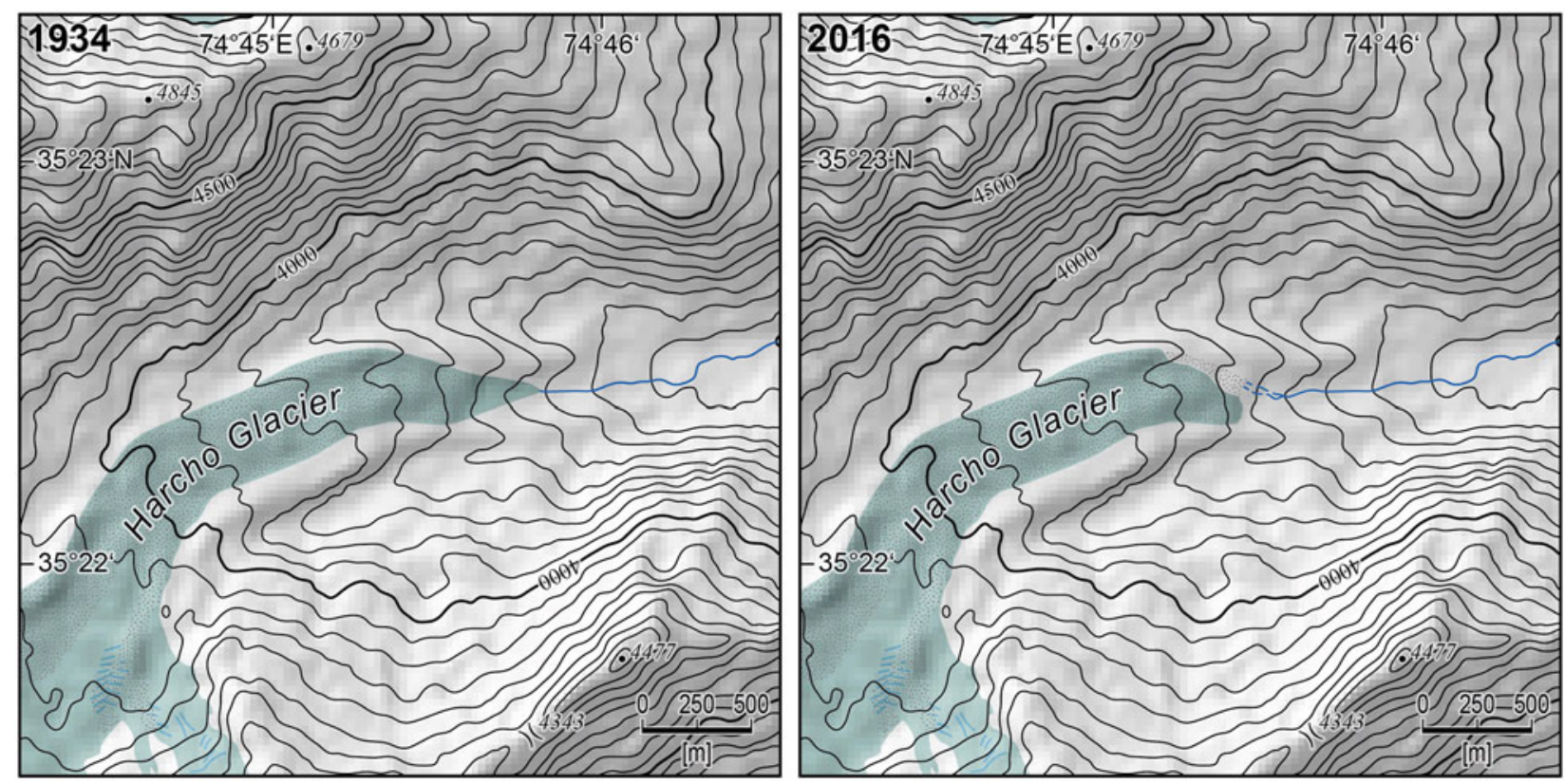

Fig. 5. Sketched map based on a comparison of the historical topographic map and recent QuickBird image of the Harcho glacier showing the change in terminus position between 1934 and 2016.

Table 1. Mass balance of glaciers in the Astore Basin (area $\geq 2 \mathrm{~km}^{2}$ ) estimated by Brun and others (2017)

\begin{tabular}{|c|c|c|c|c|c|c|c|}
\hline S. No. & Glacier name & Lat ${ }^{\circ} \mathrm{N}$ & Lon ${ }^{\circ} \mathrm{E}$ & $Z \min (m$ a.s.l. $)$ & Zmax (m a.s.l.) & Area (sq. km.) & MB (m w.e. $\left.a^{-1}\right)$ \\
\hline 1 & Toshain & 35.1579 & 74.5156 & 3707 & 6279 & 44.48 & $-0.33 \pm 0.16$ \\
\hline 2 & Chungpare & 35.2769 & 74.6885 & 2949 & 6751 & 23.62 & $+0.16 \pm 0.18$ \\
\hline 3 & Bazhin & 35.2259 & 74.6373 & 3344 & 6633 & 18.35 & $+0.13 \pm 0.19$ \\
\hline 4 & Ghughuel & 35.0801 & 74.5367 & 3997 & 6109 & 10.34 & $+0.01 \pm 0.18$ \\
\hline 5 & Sachen & 35.3281 & 74.7465 & 3404 & 5530 & 9.32 & $-0.04 \pm 0.17$ \\
\hline 6 & Unnamed Glacier 1 & 35.1138 & 74.5594 & 3890 & 5892 & 5.12 & $-0.18 \pm 0.20$ \\
\hline 8 & Unnamed Glacier 2 & 35.0370 & 74.5417 & 4506 & 5191 & 4.79 & $+0.10 \pm 0.26$ \\
\hline 9 & Unnamed Glacier 3 & 35.2770 & 75.0142 & 4128 & 5016 & 4.09 & $-0.22 \pm 0.20$ \\
\hline 10 & Unnamed Glacier 4 & 35.2078 & 74.5247 & 4365 & 6821 & 3.60 & $+0.10 \pm 0.24$ \\
\hline 11 & Unnamed Glacier 5 & 35.6027 & 74.8158 & 4466 & 5308 & 2.92 & $-0.13 \pm 0.24$ \\
\hline 12 & Harcho & 35.3595 & 74.7351 & 3750 & 4965 & 2.84 & $+0.03 \pm 0.24$ \\
\hline 13 & Unnamed Glacier 6 & 35.2992 & 74.9808 & 4027 & 5219 & 2.65 & $-0.16 \pm 0.26$ \\
\hline 14 & Unnamed Glacier 7 & 35.4752 & 74.9531 & 4227 & 5075 & 2.45 & $-0.14 \pm 0.28$ \\
\hline 16 & Unnamed Glacier 8 & 35.5679 & 74.8546 & 4463 & 5348 & 2.38 & $-0.23 \pm 0.26$ \\
\hline 17 & Unnamed Glacier 9 & 35.3141 & 75.0651 & 4472 & 5175 & 2.35 & $-0.35 \pm 0.29$ \\
\hline 18 & Unnamed Glacier 10 & 35.3286 & 75.0512 & 4084 & 5218 & 2.21 & $-0.15 \pm 0.24$ \\
\hline 19 & Unnamed Glacier 11 & 35.3153 & 74.9778 & 4093 & 5181 & 2.15 & $-0.12 \pm 0.26$ \\
\hline
\end{tabular}

Lat, Lon, Zmin and Zmax are Latitude, Longitude, Minimum elevation and Maximum elevation (a.s.I.), respectively.

elevation changes of each measured location. Based on a comparison of a historical topographic map from 1934 at a scale of 1: 50000 (Finsterwalder, 1937) with the QuickBird satellite data from 2016, the glacier terminus has retreated $368 \mathrm{~m}$ (Fig. 5).

Table 1 presents the annual average mass balance of 19 glaciers $\left(\geq 2 \mathrm{~km}^{2}\right)$ derived by Brun and others (2017) for 2000-2016. These glaciers cover $\sim 60 \%$ of the total glaciated area of the Astore Basin. The annual mass balance of these glaciers was estimated using ASTER DEMs, and vary between $-0.35 \pm 0.29$ and $+0.32 \pm 0.26 \mathrm{~m}$ w.e. $\mathrm{a}^{-1}$. The area-weighted average annual mass balance of all these glaciers is almost zero in the study period. Eleven of the observed 19 glaciers show negative mass balance. The largest glacier (the Toshain glacier, with an area $44.48 \mathrm{~km}^{2}$ ) shows a negative mass balance in contrast to the slight positive mass balance of glaciers with more than $10 \mathrm{~km}^{2}$. Seven of the nine glaciers with area $<3 \mathrm{~km}^{2}$ show a negative mass balance, while only four of the remaining ten glaciers $(>3$ $\mathrm{km}^{2}$ ) show negative mass balance. These results suggest that most of the small glaciers $\left(<3 \mathrm{~km}^{2}\right)$ are losing mass. In addition, the direct observation of the Harcho glacier confirmed minor mass loss compared with almost equivalent results of insignificant mass change within the uncertainty range derived from ASTER DEM over the observed period.

\section{DISCUSSION}

The lack of mass-balance measurements and the paucity of ground data hinders our understanding of current glacier 
behaviour in the northwestern Himalaya (Phillips and others, 2000; Shroder and others, 2000; Schmidt and Nüsser, 2009; Hewitt, 2011; Muhammad and Tian, 2016; Nüsser and Schmidt, 2017), leading to ambiguous future projections. Previous studies in the area did not investigate mass balances but instead focused on changes in terminus positions, ablation zones, formation of rock glaciers and the impact of monsoons on glaciers, and most are limited to the more accessible glaciers in the Astore Basin, such as Sachen and Chungphare (Farhan and others, 2015; Muhammad and Tian, 2016; Nüsser and Schmidt, 2017). This study deals with a relatively small nonsurging glacier that is adjacent to Sachen, with similar topography and debris cover but no history of ground measurements in the literature.

To the best of our knowledge, this is the first remotesensing and ground-based data comparison for massbalance measurements between 1999 and 2016 in the north-western Himalaya, using well-suited geodetic methods. One-time data are freely available for the oldest near-global comparatively high-resolution remote-sensing SRTM DEM, thereby providing the initiative to obtain further field-based mass-balance measurements in the region. The selection of debris-covered glacier enables us to understand the impact of debris cover on surface elevation change. These results were also compared to validate the mass balance derived for 19 individual glaciers $\left(\geq 2 \mathrm{~km}^{2}\right.$ area) from ASTER DEMs in the same period (Brun and others, 2017). Terminus position change was observed for an extended period between 1934 and 2016.

The north-western Himalayan Mountains are adjacent to the Karakoram Mountains, and several recent studies have suggested balanced glacier conditions or slight mass losses in Karakoram glaciers (Cogley, 2012; Kääb and others, 2015; Bolch and others, 2017; Zhou and others, 2017). Our elevation change observations for the rough glacier surface from the terminus to $\sim 3850 \mathrm{~m}$ a.s.l. reveal a locally heterogeneous pattern, with a relatively smooth transition from thinning to thickening going from debris-covered to clean ice in the middle to upper portions of the glacier (Fig. 3). At the transition from the debris-covered to debrisfree part ( $4050 \mathrm{~m}$ a.s.l.), the surface elevation change was $-0.26 \mathrm{~m} \mathrm{a}^{-1}$ and $-0.20 \mathrm{~m} \mathrm{a}^{-1}$, respectively (the debrisfree part showed surface elevation change of $-0.12 \mathrm{~m} \mathrm{a}^{-1}$ before SRTM C-band penetration correction).

The interpolated full-glacier and penetration-corrected mass balance of $-0.08 \pm 0.07 \mathrm{~m}$ w.e. $\mathrm{a}^{-1}$ is the lowest in the Himalaya but similar to recent findings in the Karakoram. This is likely to be due to regional climatic similarities to the adjacent Karakoram region, where glacial changes are also small. These estimates contrast in particular with the rapidly thinning glaciers in the central and eastern Himalaya. Observations of glaciers in Spiti-Lahaul (to the east of the study region, in the western Himalaya) show a mass loss of -0.7 to $-0.8 \mathrm{~m}$ w.e. $\mathrm{a}^{-1}$ between 1999 and 2004 (Berthier and others, 2007). The recent mass-balance estimates for this region during 2003-08 and 1999-2011 show significantly negative results, that is $-0.49 \pm 0.12$ and $-0.53 \pm 0.16 \mathrm{~m}$ w.e. $\mathrm{a}^{-1}$ (Gardelle and others, 2013; Kääb and others, 2015), respectively, but are lower than observations from earlier periods. In addition, the glaciers of both the Astore Basin and the Kang Yatze Massif in Ladakh experienced rapid retreating trends, with area losses of $14 \%(0.3 \%$ $\mathrm{a}^{-1}$ ), between 1969 and 2010 (Schmidt and Nüsser, 2012). Similarly, the mass loss in the eastern Himalaya (Eastern
Nyaingentanglha) is $-1.34 \pm 0.29 \mathrm{~m}$ w.e. $\mathrm{a}^{-1}$, which was the most negative in the Himalaya between 2003 and 2009 (Kääb and others, 2015). This study estimated precise glacier changes and might be helpful in future water resource and hazard management (Tian and others, 2017). Further temporal and spatial extensions of the study are necessary to improve our understanding of glaciers in the western part of the Himalayan and Karakoram ranges.

Our ground observations help reduce the uncertainty in glacier mass balance and allows for comparison and evaluation with earlier findings. The spatial distribution of surface elevation changes within each $50 \mathrm{~m}$ elevation contour in our field-based results of Harcho glacier agree within their uncertainties with the remote-sensing estimates by Brun and others (2017) (Fig. 3), though the uncertainties are significant on the glacier scale. The disagreement in height change in the central part of glacier (Fig. 3) suggests that bias is present in either the SRTM DEM or ASTER results used in this study. The use of dGPS helped to reduce the uncertainty in the estimated mass balance. Most of the uncertainty in our results is due to the use of SRTM as one-time data, which could be reduced using repeated dGPS surveys for mass-balance studies. Considering the uncertainty in our results, we expect that Harcho glacier experienced a slight mass loss rather than gain as derived by Brun and others (2017).

As well as observing both thinning and thickening on one glacier, we note that the mass balance of neighbouring glaciers in the Astore Basin observed by Brun and others (2017) is also heterogeneous. The largest glacier (Toshain) shows the second most negative mass balance in contrast to the observed slightly positive mass balance of other large glaciers. Recent observations in the ablation zone of the nearby Sachen glacier agree with the results of this study (Muhammad and Tian, 2016). The extensive debris coverage and the combined climate effects of the westerlies and South Asia monsoon (similar to the Karakoram glacial setting) are the most likely reasons for the limited glacier retreat in the western Himalaya. These changes are also consistent with recent insignificant changes in temperature and precipitation records reported in the Astore Basin (Muhammad and Tian, 2016).

\section{CONCLUSIONS}

This study estimates the mass balance of Harcho glacier in the northwestern Himalaya using comparisons of dGPS and SRTM 30 m DEM data covering the period between 1999 and 2016. The results are compared with mass-balance estimates derived by Brun and others (2017). The surface elevation changes of the Harcho glacier show complex patterns from the terminus to the top. The changes vary heterogeneously in the lower part up to $3800 \mathrm{~m}$ a.s.l., exhibit relatively smooth and significant thinning up to $4200 \mathrm{~m}$ a.s.l. and transition to thickening in the upper parts. Extrapolation to the full glacier area indicates a slight overall thinning and a mass loss of $-0.08 \pm 0.07 \mathrm{~m}$ w.e. $\mathrm{a}^{-1}$ during the study period. These results are more negative than those derived from Brun and others (2017) using ASTER $\mathrm{DEM}$, that is $+0.03 \pm 0.24 \mathrm{~m}$ w.e. $\mathrm{a}^{-1}$. However, our ground observations have lower uncertainty relative to those from remote sensing alone (Brun and others, 2017). These changes suggest that glaciers in the north-western Himalaya are also slightly losing mass and are comparable with the adjacent Karakoram region over the 17 years 
(1999-2016). As our study covers $\sim 60 \%$ of the glaciers in the Astore Basin, some uncertainty may remain for the entire basin. Long-term changes suggest that the slight changes in recent years (Muhammad and Tian, 2016) are in contrast to substantial losses in the past. In addition, future measurements in comparison with historical stereo images (Hexagon), elevation data (e.g. SRTM, etc.) and stereo images (e.g. ASTER) will minimize uncertainties and help to extend glacier observations in the region.

\section{ACKNOWLEDGEMENTS}

This work is funded by the National Natural Science Foundation of China (grant no. 41530748, 41671072, and no. 41761144075). We acknowledge the freely available, recently released SRTM $30 \mathrm{~m}$ elevation data from http:// www.earthexplorer.usgs.gov, provided courtesy of NASA JPL, and the Sentinel-2 satellite data, provided by the European Space Agency at http://www.scihub.copernicus. eu/dhus/\#/home. We also acknowledge Fanny Brun for providing mass-balance results of glaciers in the Astore Basin. We are thankful to the scientific editor Hamish Pritchard and four anonymous reviewers for their constructive review. We are also thankful to Kenneth Hewitt and Graham Cogley for their valuable suggestions on the early version of the manuscript. The first author also acknowledges funding to perform field surveys in the Astore Valley, north-western Himalaya, northern Pakistan.

\section{AUTHOR CONTRIBUTIONS}

Sher Muhammad and Lide Tian designed the study. Sher Muhammad performed the analyses and wrote the manuscript. Marcus Nüsser provided historical photos and the sketch map. Lide Tian and Marcus Nüsser commented on and edited the manuscript.

\section{CONFLICTS OF INTEREST}

The authors declare no conflict of interest.

\section{REFERENCES}

Bader H (1954) Sorge's Law of densification of snow on high polar glaciers. J. Glaciol., 2(15), 319-323.

Berthier E and 5 others (2007) Remote sensing estimates of glacier mass balances in the Himachal Pradesh (Western Himalaya, India). Remote Sens. Environ., 108(3), 327-338.

Bhambri R and Bolch T (2009) Glacier mapping: a review with special reference to the Indian Himalayas. Prog. Phys. Geogr., 33(5), 672-704. (doi:10.1177/0309133309348112).

Bhutiyani M (1999) Mass-balance studies on Siachen glacier in the Nubra valley, Karakoram Himalaya, India. J. Glaciol., 45(149), 112-118.

Bolch T and 11 others (2012) The state and fate of Himalayan glaciers. Science, 336(6079), 310-314 (doi:10.1126/science.1215828).

Bolch T, Pieczonka T, Mukherjee K and Shea J (2017) Brief communication: glaciers in the Hunza catchments (Karakoram) have been nearly in balance since the 1970s. Cryosphere, 11(1), 531-539.

Bonanno R, Ronchi C, Cagnazzi B and Provenzale A (2014) Glacier response to current climate change and future scenarios in the northwestern Italian Alps. Regional environ. change, 14(2), 633-643.
Brun F, Berthier E, Wagnon P, Kääb A and Treichler D (2017) A spatially resolved estimate of High Mountain Asia glacier mass balances, 2000-2016. Nat. Geosci., 10(9), 668.

Cogley JG (2009) Geodetic and direct mass-balance measurements: comparison and joint analysis. Ann. Glaciol., 50(50), 96-100.

Cogley JG (2012) Glaciology: no ice lost in the Karakoram. Nat. Geosci., 5(5), 305.

Cogley JG and 9 others (2011) Glossary of glacier mass balance and related terms, IHP-VII technical documents in hydrology No. 86, IACS Contribution No. 2. UNESCO-IHP, Paris.

Dehecq A and 5 others (2016) Elevation changes inferred from TanDEM-X data over the Mont-Blanc area: Impact of the X-band interferometric bias. IEEE J. Sel. Top. Appl. Earth Obs. Remote Sens., 9(8), 3870-3882.

Farhan SB, Zhang Y, Ma Y, Guo Y and Ma N (2015) Hydrological regimes under the conjunction of westerly and monsoon climates: a case investigation in the Astore Basin, Northwestern Himalaya. Clim. Dynam., 44(11-12), 3015-3032.

Finsterwalder R (1937) Die gletscher des nanga parbat, glaziologische arbeiten der deutschen himalaya-expedition 1934 und ihre ergebnisse. Z. Gletsch, 25, 57-108.

Fowler $\mathrm{H}$ and Archer D (2006) Conflicting signals of climatic change in the Upper Indus Basin. J. Clim., 19(17), 4276-4293.

Fujita K and Nuimura T (2011) Spatially heterogeneous wastage of Himalayan glaciers. Proceedings of the Na. Acad. Sci., 108 (34), 14011-14014.

Gardelle J, Berthier E and Arnaud Y (2012) Impact of resolution and radar penetration on glacier elevation changes computed from DEM differencing. J. Glaciol., 58(208), 419-422.

Gardelle J, Berthier E, Arnaud Y and Kääb A (2013) Region-wide glacier mass balances over the Pamir-Karakoram-Himalaya during 1999-2011. Cryosphere, 7(6), 1885-1886.

Gardner AS and 9 others (2013) A reconciled estimate of glacier contributions to sea level rise: 2003 to 2009. Science, 340 (6134), 852-857.

Hewitt K (2007) Tributary glacier surges: an exceptional concentration at Panmah Glacier, Karakoram Himalaya. J. Glaciol., 53 (181), 181-188.

Hewitt K (2011) Glacier change, concentration, and elevation effects in the Karakoram Himalaya, Upper Indus Basin. Mt. Res. Dev., 31(3), 188-200.

Huss M (2013) Density assumptions for converting geodetic glacier volume change to mass change. Cryosphere, 7(3), 877-887.

Immerzeel WW, Pellicciotti F and Bierkens MFP (2013) Rising river flows throughout the twenty-first century in two Himalayan glacierized watersheds. Nat. Geosci. 6(9), 742-745.

Kääb A, Berthier E, Nuth C, Gardelle J and Arnaud Y (2012) Contrasting patterns of early twenty-first-century glacier mass change in the Himalayas. Nature, 488(7412), 495-498.

Kääb A, Treichler D, Nuth C and Berthier E (2015) Brief communication: contending estimates of 2003-2008 glacier mass balance over the Pamir-Karakoram-Himalaya. Cryosphere, 9 (2), 557-564

Kaser G, Cogley JG, Dyurgerov MB, Meier MF and Ohmura A (2006) A mass balance of glaciers and ice caps: consensus estimates for 1961-2004. Geophys. Res. Lett., 33(19), L19501.

Khan A, Naz BS and Bowling LC (2015) Separating snow, clean and debris covered ice in the Upper Indus Basin, HindukushKarakoram-Himalayas, using Landsat images between 1998 and 2002. J. Hydrol., 521, 46-64.

Kulkarni AV and Bahuguna I (2002) Correspondence. Glacial retreat in the Baspa basin, Himalaya, monitored with satellite stereo data. J. Glaciol., 48, 171-172.

Kulkarni AV, Rathore B, Singh S and Bahuguna I (2011) Understanding changes in the Himalayan cryosphere using remote sensing techniques. Int. J. Remote Sens., 32(3), 601-615.

Lutz AF, Immerzeel $W$, Kraaijenbrink $P$, Shrestha $A B$ and Bierkens MF (2016) Climate change impacts on the upper Indus hydrology: sources, shifts and extremes. PLOS ONE, 11 (11), e0165630. 
Mountain Research Initiative, Elevation dependent warming working group (Pepin and 20 others) (2015) Elevation-dependent warming in mountain regions of the world. Nat. Clim. Change, 5(5), 424-430 (doi:10.1038/nclimate2563).

Muhammad S and Tian L (2016) Changes in the ablation zones of glaciers in the western Himalaya and the Karakoram between 1972 and 2015. Remote Sens. Environ., 187, 505-512.

Muhammad S, Gul C, Javed A, Muneer J and Waqar MM (2013) Comparison of glacier change detection using pixel based and object based classification techniques. 2013 Int. Geosci. Remote Sens. Symp., (IGARSS) IEEE Int., 4118-4121.

Nüsser M and Schmidt S (2017) Nanga parbat revisited: evolution and dynamics of sociohydrological interactions in the Northwestern Himalaya. Ann. American Assoc. Geograph., 107, 403-415.

Oerlemans J (2001) Glaciers and climate change. CRC Press.

Phillips WM and 5 others (2000) Asynchronous glaciation at Nanga Parbat, northwestern Himalaya Mountains, Pakistan. Geology, 28(5), 431-434.

Pratap B, Dobhal DP, Bhambri R, Mehta M and Tewari VC (2016) Four decades of glacier mass balance observations in the Indian Himalaya. Reg. Environ. Chang., 16(3), 643-658 (doi: 10.1007/s10113-015-0791-4).

Rankl M, Kienholz C and Braun M (2014) Glacier changes in the Karakoram region mapped by multimission satellite imagery. Cryosphere, 8(3), 977-989.

Rodriguez E, Morris CS and Belz JE (2006) A global assessment of the SRTM performance. Photogramm. Eng. Remote Sens., 72(3), 249-260.

Schmidt S and Nüsser M (2009) Fluctuations of Raikot Glacier during the past 70 years: a case study from the Nanga Parbat massif, northern Pakistan. J. Glaciol., 55(194), 949-959.
Schmidt S and Nüsser M (2012) Changes of high altitude glaciers from 1969 to 2010 in the trans-Himalayan Kang Yatze Massif, Ladakh, northwest India. Arct. Antarct. Alp. Res., 44(1), 107-121.

Schmidt $S$ and Nüsser M (2017) Changes of high altitude glaciers in the trans-Himalaya of ladakh over the past five decades (1969-2016). Geosciences. (Basel), 7(2), 27 (doi:10.3390/geosciences7020027).

Shroder JF, Bishop MP, Copland L and Sloan VF (2000) Debris-covered glaciers and rock glaciers in the Nanga Parbat Himalaya, Pakistan. Geogr. Annaler: Series A, Phys. Geograph., 82(1), 17-31.

Stocker TF and 9 others (2013) climate change. 2013: the physical science basis. Contribution of working group I to the fifth assessment report of the intergovernmental panel on climate change.

Tian L and 5 others (2014) Direct measurement of glacier thinning on the southern Tibetan Plateau (Gurenhekou, Kangwure and Naimona'Nyi glaciers). J. Glaciol., 60(223), 879-888.

Tian L and 9 others (2017) Two glaciers collapse in western Tibet. J. Glaciol., 63(237), 194-197.

Vijay S and Braun M (2016) Elevation change rates of glaciers in the Lahaul-Spiti (Western Himalaya, India) during 2000-2012 and 2012-2013. Remote Sens., 8(12), 1038.

Zaman QU and Liu J (2015) Mass balance of Siachen Glacier, Nubra valley, Karakoram Himalaya: facts or flaws? J. Glaciol., 61(229), 1012-1014.

Zhou Y, Li Z and Li J (2017) Slight glacier mass loss in the Karakoram region during the 1970 s to 2000 revealed by $\mathrm{KH}-9$ images and SRTM DEM. J. Glaciol., 63(238), 331-342.

Zhu D, Tian L, Wang J, Wang Y and Cui J (2014) Rapid glacier retreat in the Naimona'Nyi region, western Himalayas, between 2003 and 2013. J. Appl. Remote Sens., 8(1), 083508-083508.

Zhu $\mathrm{H}$ and 12 others (2019) Trees record changes of the temperate glaciers on the Tibetan Plateau: potential and uncertainty. Global Planet. Change, 173, 15-23. 